\title{
Adolescents Strength Profile of Hope Based on Demographic Factors
}

\section{Dody Hartanto, Sunaryo Kartadinata, Ahman, Ilfiandra}

\author{
AUTHOR CORESPONDENCES: \\ Dody Hartanto \\ Universitas Ahmad Dahlan \\ Jalan Kapas Nomor 9, Semaki, \\ Umbulharjo, Yogyakarta, Indonesia \\ Email: dody.hartanto@bk.uad.ac.id \\ Sunaryo Kartadinata \\ Universitas Pendidikan Indonesia \\ Jalan Setiabudhi Nomor 229, Isola \\ Sukasari, Isola, Sukasari, Bandung, \\ Jawa Barat, Indonesia \\ Email:profsunaryo@gmail.com \\ Ahman \\ Universitas Pendidikan Indonesia \\ Jalan Setiabudhi Nomor 229, Isola \\ Sukasari, Isola, Sukasari, Bandung, \\ Jawa Barat, Indonesia \\ Email:ahman@upi.edu \\ Ilfiandra \\ Universitas Pendidikan Indonesia \\ Jalan Setiabudhi Nomor 229, Isola \\ Sukasari, Isola, Sukasari, Bandung, \\ Jawa Barat, Indonesia \\ Email: ilfiandra@upi.edu \\ Halaman
}

111-118

\begin{abstract}
This research aims to reveal 'hope' of Indonesian adolescents especially in Bantul regency of Special Region of Yogyakarta. Data were gathered from 106 adolescents consisting of 38 males and 68 females (16-18 years old) from high schools. The instruments of this study was a hope scale in the form of semantic deferential scale ranged from 1 to $8(1=$ very inappropriate, 8 = very appropriate). The data analysis of this study was descriptive statistics. The result of the study showed that the hope of female students is higher than male students. In agency thinking, male students are higher than female students, otherwise, in pathways thinking, female students are higher than male students. Based on the parents' occupation, those who work in private sector have high hope. Conversely, the students whose parents are farmers have a low hope. The lowest scale of pathways thinking was obtained by the students whose parents are farmers as well as in the agency showed that the students whose parents are labours obtained the lowest scale.
\end{abstract}

Keywords: the strength of hope, adolescents, demography factor

\section{INTRODUCTION}

Hope is a remarkable thing to be discussed, to be written and to be narrated among mythology, religion, philosophy, education, and science. Over the past twenty years ago, the scholars attempted to conceptualising and measuring hope. The attempts are made to achieve a comprehensive understanding and set eyes on the effects of children, adolescents and adults life. Mowrer (1960) and Lopez \& Snyder (2003) asserts that hope tends to be based on behavioural point of view. However, hope is the part of affective domains and another form of reinforcement. It is based on the experiment conducted on animals. Through the stimulus and response paradigm, hope is associated with the principle of pleasure and satisfaction. On the other hand, 
"the enduring belief in the attainability of fervent wishes, in spite of the dark urges and rages which mark the beginning of existence" (Erikson, 1964; Lopez \& Snyder, 2003) describes that hope is a thought or belief that sustains an individual in achieving goals. Furthermore, he also puts the hope in a developmental context that it has emerged since birth. Moreover, he explains that the internal conflict with the individual is possibly happens due to the hope.

Study on the hope is also conducted by ShazlySavahl (2013) in South Africa towards 566 adolescents (age 1417) Cape Town. The study explores the relationship between community violence, the hopeand well-being. In this paper, the researcher focuses on the use of Synder's Children Hope Scale. Thus, the result displays a positive relationship between children's hope towards well-being.

In Asia, there are two studies conducted by researchers from Philippines and Korea. In the Phillipines, Allan B. I Bernardo and Alicia F. Estrellado (2014) carried out study focuses on testing The hope scale instrument towards the low educated individuals (this paper tries to explore scale result of Hope). Based on the study, it is shown that there is a low result of the internal consistency. The participant of thisstudyis adult. The data collected from 362 participants (age 16 - 60). In Korea, Tack-Ho, Sang, Kumlan, Seungkook, \&Ana (2005) towards 2.667 students illustrates that hope and teacher supports are significantly influenced the children' resilience towards maladaptive behaviour in groups, especially at school. On the other hand, research conducted in Minnesota of 36.549 students in grade six, nine and twelve. This study focuses on two things 1) hope and violence, 2) comparison of hope based on gender and ethnicity.

Based on the various studyexplained above, we can conclude that the hope plays a vital role in the development of one's life. Most of the study mentioned, focus on Hope scale rather than participants' gender. The only study on hope that focuses on gender has done by Synder (Hoza et al., 1997; Valle et al., 2004; Verna, 2006). Although numerous studies have been done in many countries around the world, there is no single study on hope conducted in Indonesia, especially in Special Region of Yogyakarta which has Javanese culture.

As a result, this study aims to conduct a strength of the hope in the systematic profile based on demography factors toward high school students in Special Region of Yogyakarta. There are three specific discussions a) the hope based on pathways thinking and agency thinking, b) the hope based on gender, and c) the hope differences based on the parents' occupation.

\section{METHOD}

Thisanalytic survey study uses quantitative design. This survey study belongs to thecross-sectionsurvey. The subjects of this study were 106 students of first-grade (grade $X$ ) inSMA Negeri 2BantulSpecial Region of Yogyakarta. This study employed purposive sampling technique. This survey is conducted using the instrument of hope scale which isadapted and modified in Indonesia. The survey is conducted based on two demographic backgrounds; gender and parents' occupation. The descriptive analysis is conducted after the survey in the classroom.

\section{RESULT AND DISCUSSION}

The hope data from the adolescents of the State Senior High School in Yogyakarta are provided in Table 1.

Table 1

The Result of Senior High School Adolescents' Hope in Yogyakarta

\begin{tabular}{lll}
\hline & AGENCY & PATHWAYS \\
\hline $\mathrm{N} \quad$ Valid & 106 & 106 \\
$\quad$ Missing & 0 & 0 \\
Mean & 13,6966 & 13,7558 \\
Median & 13,9772 & 13,7336 \\
Std. & 2,31678 & 2,38135 \\
Deviation & & \\
\hline
\end{tabular}

The result shows that on the two hope dimension they have, the pathways thinking is better than the agency thinking. It means the adolescents tend to have planned for their future rather than willpower. Meanwhile, the result of more detail statistic examined shows that the agency score of the male students is higher than the score of the female students' agency score. Although it seems typical, the agency score of male students is 13.76446 , and the 
agency score of female students is 13.65871 . There is 0.10575 as its difference. In contrast, with the agency data in the pathways dimension, it is known that female students have a higher result. The data show that pathways thinking on the female students get higher result, 13.88230. Meanwhile, male students only get the pathways result as 13.52935 . There is 0.35295 as its difference. Further, the score of hope between male and female students are shown in Table 2.

Table 2

The Hope Result on the Students Based on Gender

\begin{tabular}{llllll}
\hline & GENDER & $N$ & Mean & $\begin{array}{l}\text { Std. } \\
\text { Deviation }\end{array}$ & $\begin{array}{l}\text { Std. Error } \\
\text { Mean }\end{array}$ \\
\hline HOPE & Male & 38 & 27,29379 & 4,230090 &, 686211 \\
& Female & 68 & 27,54106 & 4,156014 &, 503991 \\
\hline
\end{tabular}

The result shows that the female students have a higher score of hope result than the male students. The female students get hope score as 27.54106 , while male students get hope score as 27.29379. The hope score difference on the male and female students of SMA Negeri 2 Bantul is 0.24727 . Then, Table 3 shows that students hope based on the parents' occupation background gets from the students whose parents work in the private sector.

Table 3

Descriptive Analysis Result for Hope Based on the Parents' Occupation

\begin{tabular}{lllll}
\hline & $N$ & Mean & $\begin{array}{l}\text { Std. } \\
\text { Deviation }\end{array}$ & Std. Error \\
\hline Entrepreneur & 21 & 26,61533 & 3,817124 &, 832965 \\
Labor & 26 & 28,21119 & 4,184399 &, 820628 \\
Private sector & 14 & 28,66543 & 3,111317 &, 831534 \\
$\begin{array}{l}\text { Civil } \\
\text { Servant/Indonesian }\end{array}$ & 28 & 28,00250 & 4,635169 &, 875965 \\
$\begin{array}{l}\text { National Armed } \\
\text { Forces/Indonesian }\end{array}$ & & & & \\
$\begin{array}{l}\text { National Police } \\
\text { Teacher/lecturer }\end{array}$ & 7 & 26,49757 & 2,579356 &, 974905 \\
Farmer & 10 & 24,66740 & 4,750650 & 1,502287 \\
Total & 106 & 27,45242 & 4,164258 &, 404469 \\
\hline
\end{tabular}

There is a tiny difference of hope result between the students whose parents work in the private sector and as entrepreneurs. Meanwhile, the lowest is from the students whose parents are farmers. It is exciting when the parents' occupation is teacher or lecturer who has high educational level is on the second lowest level of hope result. The variant analysis of hope is (F) 1.701 with the significance level 0.141 . The lowest pathways score of the students whose parents are farmers and teacher/lecturer and Civil Servant/Indonesian National Armed Forces/Indonesian National Police is not better than the students' whose parents work in the private sector. On the dimension of pathways, the variants analysis score is 2.367 with significance 0.045 . The agency accumulation shows that the students whose parents are labour have the highest agency rather than the others. The analysis score variant is 0.990 and the significance 0.428 .

Hope is the fundamental concept in achieving the aims and the success of one's life. Some studies have conducted in some settings and the psychologist attributes attached to it. The study which is conducted to the adolescents in the Senior High School in BantulRegency Special Region of Yogyakarta shows that the hope of the female students is higher than the male students'. While the hope of adolescents whose parents work in private sector is the highest than those who are entrepreneurs, labours, Civil Servant/Indonesian National Armed Forces/Indonesian National Police, teacher/lecturer and the lowest belongs to the farmers.

The result of analysis by Gallup Student Poll and by Lopez et al. (2010; Kristina Schmid Callina et al.: 2014), by the survey method toward not less than 240.000 students at the level of 5 to 12 shows that hope has strong correlation indicated by self ef? cacy, self-regulation, dan well-being. In the end, hope could also ultimately affect the academic success, academic competence and the sports achievement in their school.

The result of the study conducted in Yogyakarta shows that there is a significant difference between pathways thinking and agency thinking. But from the result accumulation is known that the score of pathways of the adolescents is higher than their score of the agency. Adolescents can make a plan to reach their goals more, but they have little will and passion. In some cases of practices conducted by Snyder (1994), a lot of adolescents have a lot of plans in their life, but they have a little will. Multidimensional factors cause it. The result of the study is different from the result of the study conducted by Sharon 
Danoff-Burg (2004) to 100black students in America (40 females and 60 males) started from 17 years old to 32 years old $(M=19.14, S D=2.22)$ gets the higher score of the agency that pathways. The results of the study on the theme of hope conducted in Tanzania on students aged 12 to 18 years old, get the same results with this study. The results of the adolescents' hope in Tanzania shows better results in pathways than the agency. The study is conducted by Priya G. Nalkurin 2009 with the setting outside the United States and Europe.

Meanwhile, the result obtained from this study contradicts with the study conducted by Honora Detris Adelabu (2008) to 661 adolescents with the background of African American. It is known that the result of the dimensions of the agency by mean of 13.4 and 1.8 SD while pathways are known to have mean 12.8 and SD 1.7. This indicates that the value of adolescents' willpower is higher than waypower.

The result of study conducted by Haroz Emily E.et al (2015) comparing the situation in three countries; Burundy, Nepal and Indonesia. The hope on children in Indonesia is still higher than the two other countries. While Nepal has children who have lower hope than in Burundy. The study conducted by Emily which explained about the hope still have not seen the whole dimension of hope. The participants in the study conducted in Indonesia takes place in Poso Sulawesi. Poso is an area that has experienced a religious conflict.

On the theory presented by Snyder(1994) and Theodore, Bartholomew, Michael, Scheell, \&Brian (2015) basically, there is no difference hope between male from female. However, there will be many factors will affect the individual progress on hope. Family factors, in this case, are parents, neighbourhood, school, friends, education, and also the aspects of the one's personality will encourage the acquisition and development of hope.

Snyder states that hope is the result of the calculation carried out by the interaction of children with caregivers, peers and teachers. Snyder; Hoza. et al. (1997) explains that the level of hope can be affected by individual contact with others. Besides, Taylor (1989) states that hopealso influenced by the ability of adaptive coping other styles. The other studyconducted bySnyder, Harris, et al., 1991;
Snyder, Hoza., et al. (1997) also find that hope positively correlates with the social nature and positive self-presentation. How high and low of hope in the study conducted by Barnum et al. ((1998; Snyder 1994) are affected by social support. Meanwhile, a study conducted by Snyder.,Hoza., et al. (1997) found that the hope correlates with social competence possessed by the individual social competence. The better individual social competence, the better hope they have. Therefore, in Staats' point of view (1989; Snyder: 2003), it needs not only quantitative approach but also qualitative approach. It is also known as an integrated approach.

Gottschalk (1974) and Lopez\&Snyder (2003) sees hope as a positive expectation that can be defined as the accumulation of a sense of optimism to achieve a specific result that perhaps happen again. Furthermore, Gottschalk adds that hope is the cosmic phenomenonor an imaginary occurrence that leads to spiritual events. Hope may become a path for an individual to be able to get out from the shackles of psychological problems as well.Meanwhile, a view of another expert, Staats(1989 and Lopez\&Snyder (2003) says that hope can be defined as the interaction between wills and expectations. Staats views hope affectively and cognitively, so he calls hope as the affective cognition (Staats\& Stassen, 1985; Snyder, 1994). In the affective aspect, Staats defines hope as the difference between positive and negative wishes or wills. Meanwhile, in the cognitive aspect, hope is seen as the communication between the wants and will. Averill,Catlin, and Chon (1990) andLopez\&Snyder (2003) describe hope as the emotional domain that governed or directed by cognitions. Through the definition made by researcherswho see the hope as something appropriate to be achieved; or something that is feasible to be attained, to be controlled, tobe seen as something important for individuals, to be accepted by the society. Averil adds that hopeis only able to be understood in the social and cultural context.

Another thought is popularised by Snyder, Irving, and Anderson(1991). They sayhope is defined as goal-directed thinking in which people perceive that they can produce routes to willd goals (pathways thinking) and the requisite motivation to use those routes (agency thinking). The statement above is emphasised by Snyder(1994) that hope is 
the motivational statement obtained from the will for successincluding two things: (1) Agency (energy to achieve goals) and (2) Pathways (plan to accomplish the goal).

Pathways' thinking is often called as the waypower that is the ability to formulate and determine the life direction. It is something that is important for the individual to overcome problems, challenges and obstacles. Meanwhile, agency thinking is often called as willpower that defined as determination and energy are required to initiate and maintain the achieved objectives of life. Pathways and agency(Chang \&DeSimone, 2001; Snyder, 2002; Lisa M. Edwards, Marquette D. Ong Cornell; Shane J. Lopez: 2007) aretwo similar things, but those are different. The statement above is not sufficientto define the hope. Moreover, Stotland (1969; Lopez; Snyder: 2003) saysthat the concept ofhope is an expectation greater than zero of achieving a goal. It can be interpreted as an expectation of something great to achieve a certain goal.In strength-based constructs point of view, hope and optimism are two different things (Scheier\& Carver, 1985; Lisa M. Edwards, D. Ong Marquette Cornell; Shane J. Lopez:2007) and self-efficacy (Bandura, 1982; Lisa M. Edwards, D. Marquette Ong Cornell; Shane J. Lopez: 2007). In Snyder's view (1994) focus on agency thinking (willpower). Thus someone's willdetermine results and success in the future. On the other hand, hope theory assumes that there must be a balance between willand pathways. The hope theory is different from self-efficacy which reflects the individual's capacity to take actions based on thewill. The will enables a person to guide in achieving specific goals (only focus on agency thinking) but notfocus on pathways thinking.

A Study conducted by Magaletta and Oliver (1999) suggests that hopeof an individual will have different perspectives in predicting three components namely well-being, optimism, and self-efficacy. The study of hope conducted by Edwards(Rand, Lopez, \& Snyder, 2006; Snyder,2002) provides an essential role in the process of individual adjustment. For adults, hope is positively correlated with psychological adjustment of an individual (Snyder, Cheavens, \&Sympson, 1997; Snyder et al., 1991; Sympson, 1999), the physical health (Barnum, Snyder, Rapoff, Mani, \& Thompson, 1998; Elliott, Witty, Herrick, \& Hoffman, 1991)as well as academic achievement and athletes sport achievement (Curry, Snyder, Cook, Ruby, and Rehm, 1997; Snyder, Sympson, Michael, \&Cheavens, 2001). However, studies of hope for adolescents have not been found. A number of limited studies conducted by Barnum et al. (1998; Lewis \&Kliewer, 1996; Snyder, Hoza, et al., 1997; Valle, Huebner, \&Suldo, 2004; Domingo, Andreas, \&Karoline, 2015), try to look at the relationship between the hope of various variables associated with selfacceptance.

Previous study on hope using six items based on Children Hope Scale instrument (CHS; Snyder, Hoza, et al., 1997; Nolutho, 2014) gathered from Euro-American children as the sample of the study. The findings of the study are summarised by Snyder (1994: Hoza, et al., 1997) suggested that children with high hope typically have low depression levels, have high self-perception, have a good athletic ability, able to maintain their physical appearance, have decent social acceptance and have high academic competence. Moreover, other study on hope gives a contribution to individual's health. The evidence of the earlier statement is the findings from Barnum et al. (1998) which state that an individual who experienced severe burning pain is easily recovered because of hope. This means that an individual who is experienced pain and has the high hope will recover medically and psychologically.

A Study on hope is also carried out by Valle et al. (2004) measuring validity and reliability of Children Hope Scale (CHS) instrument on African - American students as the research participants. The result of the study is valid and reliable. Meanwhile, Lisa M. Edwards et al. (2007) also studyed the hope on 135 Hispanic children (Latin America). It shows that Children Hope Scale (CHS) has a positive correlation with life satisfaction, friends and family supports, and optimism.

Not only in America, but also in Europe we can discover the study onhope. It indicates the importance of hope in individual's life. Moreover, based on the study in Ukraine on 200 students of the sixth-grade (teenagers) of Donetsk and Lviv in 2005 found that the hope correlates to six domains of individual aspirations, and material possessions, and physical well-being. While the study conducted by Susana C. Marques et al. (2014)in Portugal of 1,012 high school students meet its validity and reliability 
of the hope scaleby Snyder. It appears that it can also be applied to the Portuguese students.

There is more study performed which attempt to compare the hope based on gender. There are varied results of these studies. The study is conducted not only in America but also other continents and countries. The study which has been done through this study shows that the hope result of the female is higher than male. The result of this study is exciting because during the periods, women in Javanese culture identical to be gentle, forgiving, obedient and narimoingpandum (accept whatever the conditions are). Women's place is at home and performs household services to which her access is limited. While men in the Javanese culture is dominant and he gains the participation in more positions than women. Men in Javanese culture have more freedom and opportunities of doing things. Although the education in Indonesia has been implementing gender equality, in practice there are still some cases in which women have many problems and limited access. The findings of this studycontradict with the initial theory proposed by Snyder(1994). It states that there is no difference between the hope of men to women. But it is understandable because during the process of child development, it will meet the different environmental and get different parenting. These results contrast with the results of study conducted by Emily E. Harozet., al. (2015). The studyis conducted by comparing three countries; Indonesia, Nepal and Burundy. Thetotal participants is 1,057; (48\% female), divided into 329 Burundy; 403 Indonesia; 325 Nepal. It shows that the individual's hope of male in Indonesia is higher than female. The studyfindings also state that the male get a higher score in hope than the female in Burundy and Nepal.

In the previous year, study conducted by Honora Detris Adelabu (2008) shows thatfemale get a higher score of hope than male in adolescents' level 11 of African American culture regarding gender.In female adolescents show the mean of 3:05 whilemale adolescents show 2.87. Meanwhile, study conducted byGu "Is, ahKemer (2012) in Turkey to 737 (407 women and 330 men) from two urban and rural schools in the city of Ankara take theme the students' hope from love perspective, esteem-related support, instrumental support, and gender. Interesting infor- mation from the study associated with this study is that the boyshave a positive contribution in hope. It means the boys in urban areas have more hope than girls. This is the same as the study conducted in the United States. The results of another study conducted in the United States by Snyder et al. (1996; Gu "IsahKemer: 2012), boys have higher hope than girls. It becomes interesting study because if it is associated with the culture, boys in Turkey have more freedom than girls in many ways. Nurmi and Pulliainen (1991; Kristina SchmidCallina, 2014; Cheryl, 2009) state that parenting by parents will directly influence the hope of adolescents in the future as well as different periods between one and another. Erikson (1959; Flanagan 2003; Kristina SchmidCallina: 2014) states that the relationship between parents and children, in the end, will reinforce hope and boost confidence in children. In a study conducted in Ukraine by Olena(2011) and Oksana \& Olga(2010), parents' occupation contributes to hope that the student earned. But, this study, the researcher has not explained the specific type of parents' occupation influencing the students' hope.Meanwhile, in the study conducted is known that the parents' occupation of the private sector is the highest. While students whose parents are farmers known to have low hope (Geraldine, 2011; Wing \&Mathew, 2015). Based on the result of the study, students' whose parents are teacher or lecturer is not better than the students' whose parents are labours in private sector. It becomes an exciting issue to discuss. Teacher and lecturer are assumed will encourage students to have more hope, but the fact is different. The lack of hope on the students whose parents are the farmer is very interesting to be studied and to be discussed. There are several possibilities related to the lack of hope in adolescents whose parents are farmers having the economic problem in their family.

Farmers, as is known, do not have fixed income due to differences in the amount of harvest. Economic problems experienced by students may affect the high and low hope. Besides the work of farmers can be attributed to the level of education, the parents' level of education ultimately affects the hope of the children. The significance of parents in the development of the adolescents or students' hope also appears in a study conducted by Priya G. Nalkur (2009) 
in Tanzania. This is also supported by Snyder (1994), he states that in children and adolescents, hope is developed in the supportive situation context of the adults around them. Proximity and affection from adults mediate solid hope. This is reinforced by study conducted in Chicago by Henrika Mc Coy (2015). This study is conducted to 489 participants of 17 years old students on average. The result of the study shows that the relationship with parents and the feeling of security in the neighbourhood have a positive impact in building hope and success in the future. Other results are given by Laura M. Padilla-Walker (2011) in which the complete parents will be more encouraging the hope of the students rather than the students' hope from a single parent's family. Besides, it is stated that the hope developed by parents or adults around adolescents and children will be positively correlated. It can be interpreted that the adolescents will have good hope when adults around them have good hope too.

The results of study conducted by Allan BI Bernardo (2014) shows that parents in the Philippines who tend to be collectivism correlate with the students' hope. This study is conducted to 362 participants, divided into 241 female and 104 male in Metro Manila. There is a similarity context between Indonesia and Philippines that have collectivism culture. The results of the study show that parents who tend to collectivism will encourage hope to their children. Another interesting study as the discussion is the background of the parents' marriage and its effect on hope. It is known that children from intact families have low levels of happiness and life satisfaction. However, the children can arrange the purpose of life, self-esteem and better hope. There are some important things to be noted and limitations in this study. First, the number of participants needs to be increased because it only comes from one school in the district of Bantul. Second, the participants areonly Javanese students, so another study with a different cultural background (multicultural) of the participants needs to be conducted. Third, the instrument used, semantic differential scale models need to be adapted to the cultural context where the data retrieval. Previous study can be directed to other demographic aspects such as the parents' educational background, parents' support, students' religion.

\section{CONCLUSION}

The result shows that hope of every individual is a unique attribute; one individual is different from another. The differences can be seen from various demographic backgrounds attached to them. The result shows that male's hope is better than female's hope.Meanwhile, the demography background of parents' occupation shows that farmers get the lowest hope. For further study, it needs to conduct another study based on another parents' demography factors such as education, marital status, religion and economic level. The study can be linked to the culture and one's hope.This study can be developed through a survey with a qualitative design. In the end, italso needs study about children and adults' hope to complete the previous study.

\section{REFERENCES}

Adela, Yarcheski \&Noreen E. Mahon. (2014). Metaanalyses of Predictors of Hope in Adolescents. Western Journal of Nursing Research, 1-24. Allan,

B. I. Bernardo. (2015). Hope in Early Adolescence: Measuring Internal and External Locus-of-Hope. Child Ind Res, 8, 699-715. Springer Science +Business Media.

Cheryl, Charles. (2009). The Ecology of Hope: Natural Guides to Building a Children and Nature Movement. Journal Science Education Technology, 18, 467-475.

Detris, Honora Adelabu. (2008). Future Time Perspective, Hope, and Ethnic Identity Among African American Adolescents. Urban Education, 43(3), 347-360.

Domingo, Va., Andreas, H., \&Karoline, S. (2015). Hope in Adolescent Careers: Mediating Effects of Work Motivation on Career Outcomes in Swiss Apprentices. Journal of Career Development, 42(5), 381-395.

Geraldine, O'Sullivan. 2011. The Relationship Between Hope, Eustress, Self-efficacy, and Life Satisfaction Among Undergraduates. Soc Indic Res, 101, $155-172$.

Gu "ls , ah Kemer \&Go "khan, Atik. (2012). Hope and Social Support in High School Students from Urban and Rural Areas of Ankara, Turkey. J Happiness Study, 13, 901-911. 
Henrika, McCoy., Elizabeth, A. Bowen. (2015). Hope in the Social Environment: Factors Affecting Future Aspirations and School Self-Ef?cacy for Youth in Urban Environments. Journal Child Adolescence Social Work, 32,131-141.

Kristina, Schmid Callina., Sara K. Johnson., Mary H. Buckingham \& Richard M. Lerner. (2014). Hope in Context: Developmental Pro?les of Trust, Hopeful Future Expectations, and Civic Engagement Across Adolescence. Journal Youth Adolescence, 43, 869-883.

Laura, M., Padilla-Walker., Sam A. Hardy., \& Katherine J. Christensen. 2011. Adolescent Hope as a Mediator Between Parent-child Connectedness and Adolescent Outcomes. Journal of Early Adolescence 31 (6), 853-879.

Lisa, M., Edwards., Marquette D. Ong., \&Cornell Shane J. Lopez. (2007). Hope Measurement in Mexican American Youth. Behavioral Sciences, 29 (2), 225-241.

Nolutho, Diko. 2014. Women in Educational Leadership: the Case of Hope High School in the Eastern Cape Province, South Africa. Educational Management Administration $\mathcal{E}$ Leadership, 42(6), 825-834.

Oksana, Yakushko \& Olga, Sokolova. (2010). Work Hope and Influences of the Career Development among Ukrainian College Students. Journal of Career Development, 36(4), 310-323.

Olena, Nikolayenko. (2011). Adolescents' Hopes for Personal, Local, and Global Future: Insights from Ukraine. Youth EO Society, 43(1), 64 -89.

Priya G. Nalkur. (2009). Adolescent Hopefulness in Tanzania Street Youth, Former Street Youth, and School Youth. Journal of Adolescent Research, 24(6), 668-690.

Raquel, Halfond., Rosalie, C.,\&Anya, Moon. (2012). Latino Parent and Adolescent Perceptions of Hoped-for and Feared Possible Selves for Adolescents. Jour-nal of Adolescent Research, 28(2), $209-240$.

Sharon, Danoff-Burg., Hazel M. Prelow., \& Rebecca R. Swenson. (2004). Hope and life Satisfaction in Black College Students Coping with Race-related Stress. Journal of Black Psychology, 30(2), 208-228.

Susana, C. Marques., Shane J. Lopez., \& J. L. PaisRibeiro. (2011). Building Hope for the Future: a
Program to Foster Strengths in Middle-school Students. Journal Happiness Study, 12, 139-152.

Tack-Ho, K., Sang, M. L., Kumlan Y., Seungkook L., $\&$ Ana P. (2005). Hope and the Meaning of Life as Influences on Korean Adolescents' Resilience: Implications for Counselors. Asia Pacific Education Research Institute, 6,(2), 143-152.

Theodore, T., Bartholomew., Michael J. Scheell., \&Brian P. C. (2015). Development and Validation of the Hope for Change Through Counseling Scale. The Counseling Psychologist, 43(5), $671-702$.

Verna, H.F. (2006). Relationships of Age and Gender to Hope and Spiritual Well-being Among Adolescents with Cancer. Journal of Pediatric Oncology Nursing, 23(4), 189-199.

Wing, H. C., \&Mathew Y. H. W. (2015). Association between Parents' Marital Status and the Development of Purpose, Hope, and Self-esteem in Adolescents in Hongkong. Journal of Family Issues, 1 -19. 